\title{
Heat Pump Application at Hydrogen Compression While using Metal Hydride Materials
}

\author{
Tomáš Brestovič ${ }^{1}$, Natália Jasminská ${ }^{1, *}$, Marián Lázár ${ }^{1}$ \\ ${ }^{1}$ Technical University of Košice, Faculty of Mechanical Engineering, Department of Power Engineering, Slovak Republic
}

\begin{abstract}
This paper discusses about the possibility of using a heat pump when compressing hydrogen with metal hydride materials. Hydrogen is absorbed into the alloy at low pressure and temperature. Increasing the temperature of the alloy by absorbed hydrogen results in a significant increase in pressure, with hydrogen desorption being carried out at an increased equilibrium pressure. A compressor working with $\mathrm{MH}$ materials requires cyclic heating of the reservoir from which hydrogen will be desorbed and absorbed.
\end{abstract}

Keywords: hydrogen; compression; heat pump; metal hydride.

\section{Introduction}

The use of hydrogen in mobile and energy applications requires solving a considerable number of obstacles, primarily including the efficient storage of a sufficient amount of hydrogen at acceptable thermodynamic conditions. In 2012, within the "FCT Program's Multiyear Research, Development and Demonstration Plan", the American Department of Energy (DOE) determined several parameters that represent technological targets for the efficient use of mobile hydrogen storage tanks to be achieved in 2020. One of them is the minimum time for the storage of 5 $\mathrm{kg}$ of hydrogen which was determined as 3.3 minutes. The minimum mass capacity should reach $5.5 \%$ and the volume capacity should be $0.04 \mathrm{~kg} \mathrm{H} / \mathrm{L}$ of the system $[1,2]$. With regard to the use of high pressures and composite materials within the pressure storage method, or the use of cryogenic temperatures (20.39 K) within the liquid storage method, progressive hydrogen storage methods have been recently gaining ground. The use of alloys that are able to form metal hydrides $(\mathrm{MH})$ at low pressures (up to $2 \mathrm{MPa}$ ) and temperatures $\left(20^{\circ} \mathrm{C}\right)$ seems to be a prospective direction to follow.

Hydrogen absorption into the alloy occurs after achieving the required pressure at which the catalytic effects of the used metals induce the dissociation of a hydrogen molecule and the subsequent diffusion of hydrogen atoms into the intermetallic lattice space $[3,4,5,6]$. The absorption process is accompanied with a slow pressure increase up to the value of absolute metal saturation. The plateau pressure, at which absorption occurs, significantly depends on the alloy temperature. The difference in plateau pressures of $\mathrm{MH}$ materials at the acceptable temperature change led to an effort to design a hydrogen compressor that would use the temperature cycle of heating and cooling of a MH storage tank $[7,8,9]$.

\section{Description of the compressor's temperature cycle}

Figure 1 shows the basic temperature cycle of a compressor using the $\mathrm{La}_{14} \mathrm{Ce}_{2} \mathrm{Ni}_{84}$ alloy that is capable of forming $\mathrm{MH}$. The cycle is drawn in the measured $\mathrm{PCl}$ (Pressure Concentration Isotherms) graphs between the temperatures of 10 and 
$50^{\circ} \mathrm{C}$. The baseline point $A$ represents the initial state of the alloy with the $0.16 \%$ concentration of the absorbed hydrogen at the pressure of 0.12 MPa. Hydrogen is absorbed into the alloy between points $A$ and $B$ and it is accompanied with the heat release. For the $\mathrm{La}_{14} \mathrm{Ce}_{2} \mathrm{Ni}_{84}$ alloy, the amount of the released reaction heat is identified by experimental measurements as $1 \mathrm{MJ} \cdot \mathrm{m}^{-3}$ of $\mathrm{H}_{2}$ (measured at $20^{\circ} \mathrm{C}$ ). Following the alloy saturation up to the concentration of $0.66 \%$, the pressure increases up to $0.2 \mathrm{MPa}$.

Further concentration increase is inappropriate, with regard to the increasing pressure gradient, as it would lead to the reduction of the compression ratio and to a useless increase of the operating pressure of the compressor (point C). Once the required concentration is reached, the alloy temperature must be increased by adding the heat.

$$
Q_{\mathrm{BC}}=\sum_{i}\left(m \cdot c_{i}\right) \cdot \Delta T+q_{\mathrm{des}} \cdot \Delta V_{\mathrm{des} \mathrm{H}_{2}}
$$

whereas $\Sigma\left(m_{i} \cdot c_{i}\right)$ is the total heat capacity of the $\mathrm{MH}$ storage tank, including the integrated heat exchanger and the absorbed hydrogen $\left(\mathrm{J} \cdot \mathrm{K}^{-1}\right)$, $\Delta T$ - the difference between the temperatures of working isotherms $(\mathrm{K}), q_{\text {des }}$ - reaction heat at hydrogen desorption $\left(\mathrm{J} \cdot \mathrm{m}^{-3}\right), \Delta V_{\text {des }} \mathrm{H} 2$ - amount of released hydrogen at the temperature increase in $\Delta T\left(\mathrm{~m}^{3}\right)$.

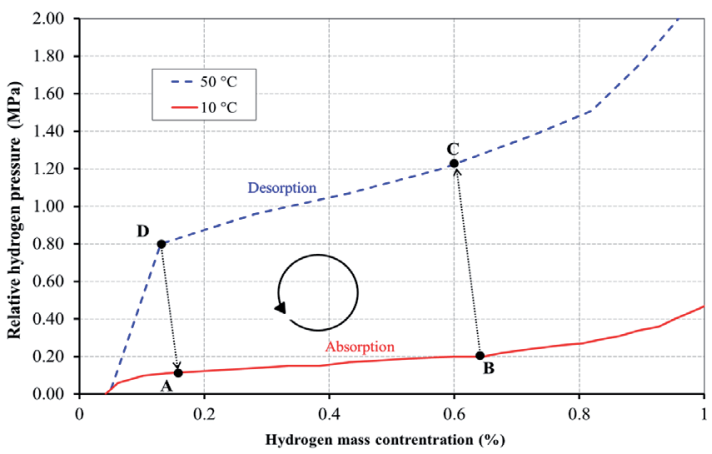

Fig. 1: Description of the temperature cycle of hydrogen compression using the La14Ce2Nis4 alloy.

As a result of supplying the heat between points $B C$, the temperature increases in $40^{\circ} \mathrm{C}$, which is reflected in the pressure increase approximately up to $1.22 \mathrm{MPa}$. Due to the desorption effect accompanied with the pressure increase, hydrogen is released in a small amount and increases the pressure of gaseous hydrogen between the alloy grains; as a result, the shift of point $C$ to the area with a lower concentration significantly depends on the grain size and on the volume of the free space between the alloy grains.

After the pressure is increased by heating the alloy, it is possible to start hydrogen desorption between points $C$ and $D$ that is accompanied with the consumption of the supplied reaction heat. Concentration decrease is only possible after achieving the value of $0.13 \%$, as at lower oncentrations the pressure decreases very quickly. The pressure in point $D$ reaches the value of $0.8 \mathrm{MPa}$; therefore, the compression ratio at hydrogen compression by the temperature cycle can be identified while using the formula

$\varepsilon_{\mathrm{k}}=\frac{p_{\mathrm{D}}}{p_{\mathrm{B}}}$

whereas $p_{D}$ is hydrogen pressure in point $\mathrm{D}(\mathrm{Pa})$, $p_{B}$ - hydrogen pressure in point $\mathrm{B}(\mathrm{Pa})$. During the operation of a cyclical compressor with the used $\mathrm{La}_{14} \mathrm{Ce}_{2} \mathrm{Ni}_{84}$ alloy within the temperature range from 10 to $50^{\circ} \mathrm{C}$ and the mass concentrations of 0.16 and $0.66 \%$, the compression ratio resulting from measurements of $\mathrm{PCl}$ curves is $\varepsilon_{\mathrm{k}}=4$.

To achieve the temperature and pressure of the baseline point A again, the storage tank must be cooled and the heat must be removed

$Q_{\mathrm{DA}}=-\left[\sum_{i}\left(m_{i} \cdot c_{i}\right) \cdot \Delta T+q_{\mathrm{abs}} \cdot \Delta V_{\mathrm{abs} \mathrm{H}_{2}}\right]$

whereas $q_{\text {abs }}$ - reaction heat at hydrogen absorption $\left(\mathrm{J} \cdot \mathrm{m}^{-3}\right), \Delta V_{\text {abs }} \mathrm{H} 2$ - amount of absorbed hydrogen at temperature decrease in $\Delta T\left(\mathrm{~m}^{3}\right)$. On the basis of the cycle, the basic concept of the compressor described in the next chapter was proposed.

\section{Conceptual design of a hydrogen compressor using a heat pump}

Creation of a cyclically operating hydrogen compressor working with $\mathrm{MH}$ materials requires meeting the following requirements:

a) continuous operation without the necessity of shutting down the flowing hydrogen at the inlet into the compressor,

b) low energy demand for reaching the significant compression 
ratio,

c) use of the alloy with a high mass concentration and with lower sensibility to gas impurities (mainly oxygen),

d) assembling an autonomous operation of the compressor.

To construct a continuously operating hydrogen compressor using $\mathrm{MH}$ materials, it is useful to use a tandem arrangement of two storage tanks, $\mathrm{MH}_{1}$ and $\mathrm{MH}_{2}$, as shown in the scheme in Figure 2. During hydrogen absorption into the $\mathrm{MH}_{1}$ storage tank, hydrogen is desorbed in the $\mathrm{MH}_{2}$ storage tank.

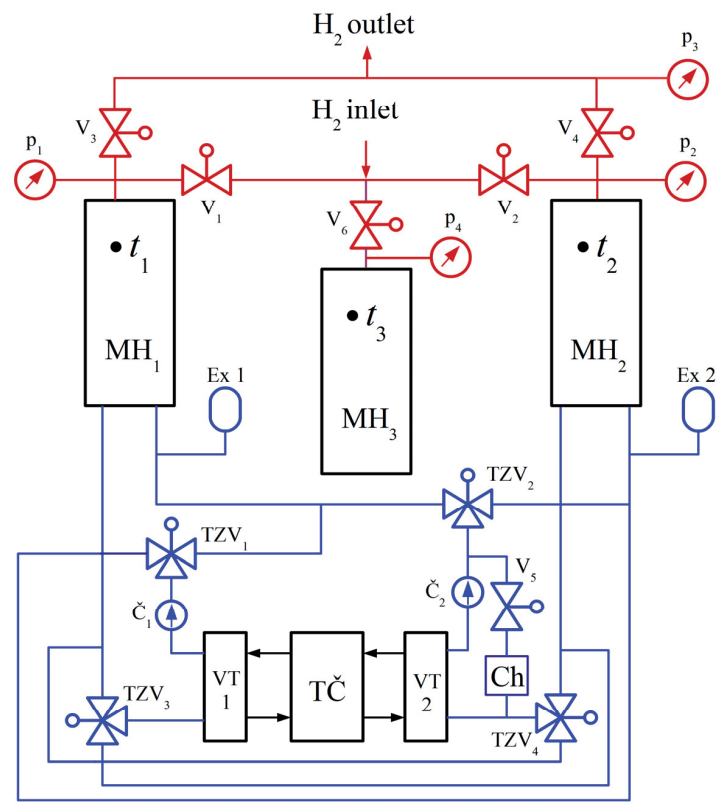

Fig. 2: Basic connection scheme of a hydrogen compressor.

With regard to the fact that during hydrogen absorption the heat is released and during the desorption the heat must be supplied, it is advisable to place a heat pump between $\mathrm{MH}_{1}$ and $\mathrm{MH}_{2}$ storage tanks that would enable heat transport between them. By using the tandem arrangement of storage tanks, it is possible to achieve continuous operation, whereas for the purpose of temporary hydrogen absorption during the heating and cooling between working points BC and DA (Figure 1) it is possible to use an auxiliary additional $\mathrm{MH}_{3}$ storage tank with natural cooling.

Compressor operation within the above described temperature range from 10 to $50^{\circ} \mathrm{C}$ facilitates the use of standard heat pumps with the
COP value approximately 3 . The consumption of electric energy for the heat transport between the storage tanks can thus be significantly eliminated, which contributes to very low energy consumption by the device.

The amount of the supplied heat, described by formulas (1) and (3), can be significantly eliminated by using alloys with high mass concentration of the stored hydrogen. Types like this facilitate the use of smaller storage tanks with lower weights which also contributes to higher energy-efficiency of hydrogen compression operation. If hydrogen is produced by water electrolysis in alkaline electrolysers, the inletting hydrogen is often contaminated with small oxygen concentrations. During a long-term operation, surface oxides are formed on the alloy grains that hinder hydrogen penetration into the metal structure and reduce the cyclical stability of the alloy. This results in the reduction of the number of operating cycles with a subsequent necessity of alloy regeneration using the oxygen reduction or by a complete alloy replacement.

To create an autonomous operation of a hydrogen compressor, it is necessary to use a control micro-computer with input-output ports for detecting the temperatures, pressures and control of opening hydrogen and three-way zone valves for transporting water from the condenser and exchanger into $\mathrm{MH}_{1}$ and $\mathrm{MH}_{2}$ storage tanks.

\section{Results}

Operation of a heat pump used in a hydrogen compressor significantly differs from the conventional use of a heat pump during the heating. The difference is mainly in jump changes in the temperatures of liquids supplied into the condenser and evaporator when switching between the heating and the cooling modes. At the Department of Energy Technology in Košice there is a currently running development of a prototype of a hydrogen compressor using $\mathrm{MH}$ materials within the APVV project. For this purpose, in cooperation with the TATRAMAT - ohrievače vody, s.r.o. company, a water-to-water heat pump with the heating power of $1.5 \mathrm{~kW}$ and the cooling power of $1.2 \mathrm{~kW}$ is being developed. R134a (weight of $900 \mathrm{~g}$ ) is used as the coolant.

The compressor has a standard operating input power of $400 \mathrm{~W}$. The cooling power is optimised for 


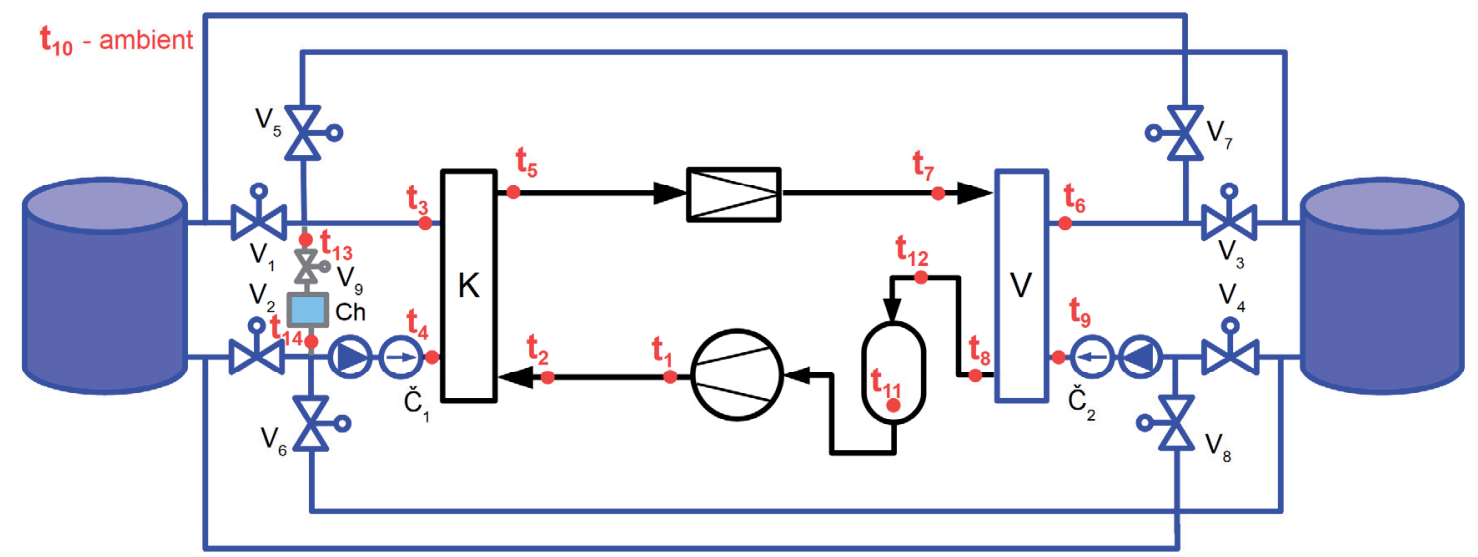

Fig. 3: Connection scheme during the initial measurement of the heat pump.

a two-stage tandem compressor. During the initial experimental measurement, the heat pump was connected as shown in the scheme in Figure 3.

For the simplification purposes, $\mathrm{MH}$ storage tanks were replaced with two freely opened tanks, whereas each one of them contained $4 \mathrm{dm}^{3}$ of demineralised water, which corresponds to the heat capacity of two MH storage tanks (1 storage tank / stage) with the alloy based on La, Ce and $\mathrm{Ni}$. When $V_{1}$ to $V_{4}$ valves are opened, water from the condenser flows into the left storage tank and water from the evaporator flows into the right storage tank. When $V_{1}$ to $V_{4}$ valves are closed and $V_{5}$ to $V_{8}$ valles are opened, there is a switch between the cooling and the heating modes. This switch induces the inlet of cold water into the condenser and of hot water into the evaporator. The measurement should thus provide a more detailed view of thermodynamic changes during the switch of individual storage tanks between the heating and the cooling modes within the storage tank temperature range from 10 to $50^{\circ} \mathrm{C}$.

Temperatures were scanned using electronic 1-wire sensors of DS18B20 type with the measurement range from -55 to $125^{\circ} \mathrm{C}$. The temperature measurement accuracy is $\pm 0.5^{\circ} \mathrm{C}$. The pressure was scanned using the Huba Control sensors with the range from $3 \mathrm{MPa}$ (pressure behind the compressor) to $1.6 \mathrm{MPa}$ (pressure behind the expansion valve). The maximum measurement accuracy is $0.5 \%$ of the sensor range. The output current signal of pressure sensors is 4 to $20 \mathrm{~mA}$ and it was conversed by a resistor into the voltage signal. The values were recorded using the Raspberry Pi PC with additional cards for 1-wire sensors and A/D converter.

As for heat pumps, the thermal power removed from the condenser is always higher than the cooling power received by the evaporator. Therefore, an additional air cooler is placed on the condenser's side and it must be turned on when the temperature exceeds $50^{\circ} \mathrm{C}$ in the storage tank that is being heated at the moment.

In the beginning of the measurement, the average temperature of water in storage tanks was $23^{\circ} \mathrm{C}$. Water flow through the condenser and the evaporator was maintained at the value of 3 I I. $\mathrm{min}^{-1}$. The curves of water temperatures at the inlet into and the outlet from the condenser and the evaporator are shown in Figure 4.

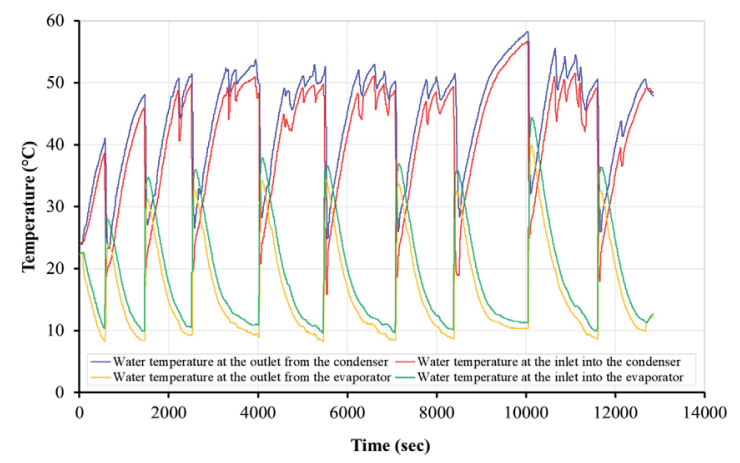

Fig. 4: Curve of water temperatures at the inlet into and at the outlet from the condenser and the evaporator.

When the required temperature of $10^{\circ} \mathrm{C}$ at the inlet into the evaporator is reached, the cooling and the heating modes were switched using the $V_{1}$ to $V_{8}$ valves. The curve clearly indicates that the 
third switch is followed by stabilisation and in order to maintain the temperature gradient of $10 / 50^{\circ} \mathrm{C}$, it is necessary to use an external cooler for additional cooling. Figure 5 represents the curve of relative pressures of the coolant behind the compressor and the expansion valve in time.

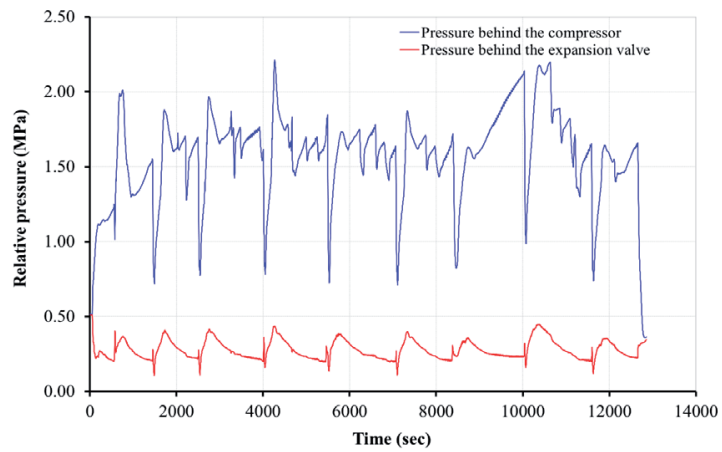

Fig. 5: Curve of pressures in the heat pump during the measurement.

The curve clearly indicates that when the storage tanks are switched, the pressure in the condenser rapidly decreases due to effect of the supplied cold water with the temperature of $10^{\circ} \mathrm{C}$ which intensifies the condensation. In the evaporator, the pressure slightly increases due to the effect of flowing water with the temperature of $50^{\circ} \mathrm{C}$ which increases the coolant's temperature after evaporation. With certain time delay, there is also an increase in the temperature in the separator before the compressor, causing pressure overshoots behind the compressor (they occur after a rapid decrease in the pressure behind the compressor).

The pressure cut-out switch located behind the compressor shuts down the compressor if the pressure exceeds $2.3 \mathrm{MPa}$. In some cases, the pressure increased almost to a critical value; nevertheless, the heat pump shut-off did not occur. During the measurement, the average COP was 3.3. The average time between the storage tank switch was 11 minutes.

For the comparison purposes, the following section describes the measurement while switching between the heating and the cooling modes of storage tanks during which the emergency stop of the compressor occurred. Figure 6 represents the curve of temperatures at the inlet into and at the outlet from the condenser and the evaporator.

The first switch of storage tank heating occurred at second 723 since the measurement commencement. Subsequently, at second 860, the emergency stop of the compressor by the pressure fuse occurred. The curve of pressures behind the compressor and the expansion valve is shown in Figure 7.

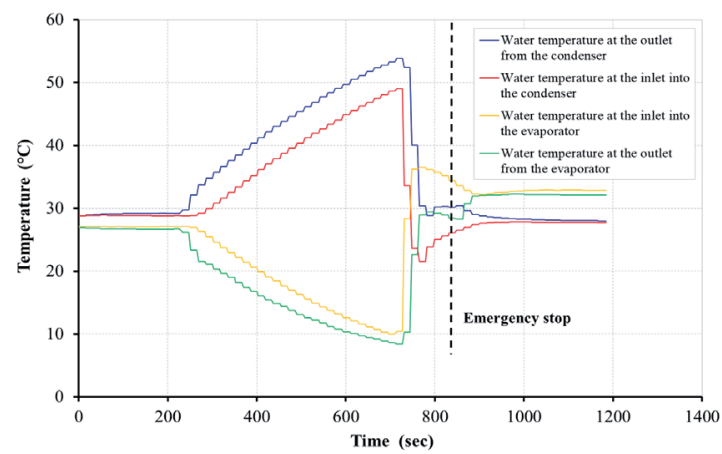

Fig. 6: Curve of water temperatures at the inlet into and at the outlet from the condenser and the evaporator during the emergency stop of the heat pump.

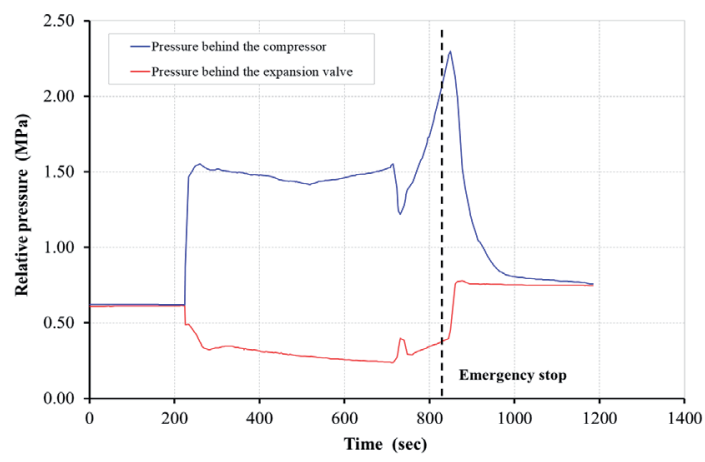

Fig. 7: Curve of pressures in the heat pump during the measurement with the emergency stop.

Temperature of water in storage tanks at the beginning of the measurement was $28^{\circ} \mathrm{C}$; it means that already during the first cycle there was a $50 / 10^{\circ} \mathrm{C}$ temperature difference between the storage tanks. When the cooling mode was switched, the temperature at the outlet from the evaporator did not decrease below $10^{\circ} \mathrm{C}$ (Fig. 8). A slightly increased temperature of the coolant before the compressor caused the increase in the coolant temperature also behind the compressor, which also reflected in a respective pressure increase.

By exceeding the pressure above the maximum allowable value of $2.3 \mathrm{MPa}$, the heat pump compressor was switched off. 


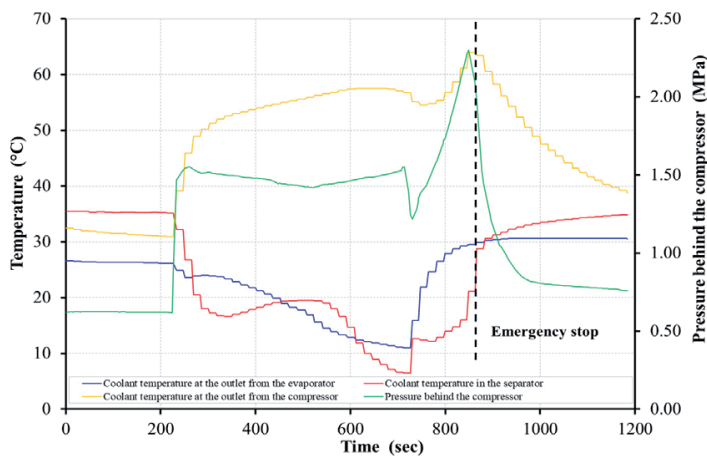

Fig. 8: Curve of water temperatures at the inlet into and at the outlet from the condenser and the evaporator during the emergency stop of the heat pump.

Emergency stop prediction can be found also in a slighter pressure decrease behind the compressor at the heating mode switch at second 730 , compared to the decrease in the stabile operation of the device.

The knowledge gained from the measurements at the heat pump outages will be subsequently used in the further research and adjustment of the device to ensure continuous operation thereof.

\section{Discussion}

The present article deals with the possibility to use a heat pump in the construction of a hydrogen compressor using the temperature cycle at hydrogen absorption and desorption into metal hydrides. In the preliminary stage, the measurement was carried out with a cyclical switching between heating and cooling of storage tanks, while maintaining the stabile operation at the average $\mathrm{COP}=3.3$. However, in the conclusion we pointed out an unstable operation of a heat pump during which there was an emergency stop of the compressor by the pressure fuse. To eliminate such deficiency, it is advisable to adjust the pump by reducing the coolant's weight or by reducing the operating temperatures down to $5 / 45^{\circ} \mathrm{C}$.

\section{Acknowledgments}

This paper was written with the financial support of the granting agency APPV within the project solution No. APVV-150202, of the granting agency VEGA within the project solution No. 1/0752/16 and of the granting agency KEGA within the project solution No. 005TUKE-4/2016.

\section{References and Notes}

[1] Mellouli, S., Askrifi, F., Dhaou, H., Jemni, A., Ben Nasrallah, S. (2006). A study of the thermal behavior of a deformable metal-hydride bed. International journal of hydrogen energy, p. 1711-1724.

[2] Cao, Z., Ouzang, L., Wang, H., Liu, J., Sun, D., Zhang, Q., Zhu, M. (2014). Advanced high-pressure metal hydride fabricated via TieCreMn alloys for hybrid tank. International journal of hydrogen energy, p. 2717 - 2728.

[3] Sarkar, A., Benerjee, R. (2005). Net energy analysis of hydrogen storage option. International journal of hydrogen energy, p. 867-877.

[4] Bouaricha, S., Huot. J., Guaz, D., Schuly, R. (2002). Reactivity during cycling of nanocrystalline Mg-based hydrogen storage compounds. Int J Hydrogen Energy; 27(9): 909-13.

[5] Grochala,W., Edwards, P.P. (2004). Thermal decomposition of the non-interstitial hydrides for the storage and production of hydrogen. Chem Rev; 104:1283-315.

[6] Imamura, H., Masanari, K., Kusuhara, M., Katsumoto, H., Sumi, T., Sakata, Y. (2005). High hydrogen storage capacity of nanosized magnesium synthesized by high energy ballmilling. J Alloys Compds; 386:211-6.

[7] Popeneciu, G., Almasan, V., Coldea, I., Lupu, D., Misan, I., Ardelean, O. (2009). Investigation on a tree-stage hydrogen thermal compressor based on metal hydrides. Journal of Physics: Conference Series 182, 012053.

[8] Lototskyy, M. V., Yartzs, V. A., Pollet, B. G., Boweman, Jr, R. C. (2014). Metal hydride hydrogen compressors: A review. International journal of hydrogen energy, p. 5818 - 5851.

\section{Biographical notes}

Tomáš Brestovič, doc., Ing., PhD., (born in 1982) is a graduate of Faculty of Mechanical Engineering. Currently works as a associate prof. at Department of Power Engineering, Faculty of Mechanical Engineering. He is actively dealing with issues regarding heat transfer, flow of liquids, novel technologies in the field of renewable sources and mathematical modelling of energy processes.

Natália Jasminská, doc., Ing., PhD., (born in 1983) is a graduate of Technical University in Košice, Faculty of Metallurgy. Currently work as a associate prof. at Department of Power Engineering, Faculty of Mechanical Engineering. She focuses in the area of thermal technique, hydrogen technology and alternative sources of energy.

Marián Lázár, doc., Ing., PhD., (born in 1985) is a graduate of Faculty Mechanical Engineering of Technical University of Košice. Currently work as a associate prof. at Department of Power Engineering. His scientific and research focus is on high temperature waste treatment and on the production and storage of hydrogen. 